\title{
Inquiry-based Teaching in Second and Foreign Language Pedagogy
}

\author{
Horng-Yi Lee \\ Department of Modern Languages and Literatures, Whittier College, Whittier, CA, USA
}

\begin{abstract}
It is the consensus among language educators that the objectives of teaching a second/foreign language (L2) put stress on the enhancement of students' communication skills and advocate the importance of interaction in the classroom. In addition to theories and methods exclusively dedicated to language instruction, the domain-independent inquiry-based teaching, a cognitive approach, can be easily and effectively integrated into the L2 classroom which echoes the concerns and needs in L2 education. Inquiry teaching is characterized by its question-answer interactive information exchanges. Instead of learning passively, it stimulates students to actively engage in cognitive and discovery learning activities. It is assumed that this active, discovery, or Socratic teaching approach promotes the dynamics in class, draws and maintains students' attention, reinforces meaningful communication, deepens and expands intellectual capacity, and facilitates learning transfer. Most importantly, it supports the development of learner's cognitive and metacognitive strategies. This technique best fits within the theme-based text and can be conducted in an expanding spiral pattern. A questionnaire was administered in a Chinese as a second language class to assess students' feedback on the effectiveness and preference of this approach and favorable findings were revealed. Students expressed enthusiasm on inquiry-based teaching and indicated that this approach reinforced their learning and understanding of the course material. Qualitative data also shows that inquiry-based teaching enhanced students' classroom engagement and fostered an effective and meaningful learning experience.
\end{abstract}

Index Terms - inquiry-based teaching, second and foreign language, language pedagogy, questioning, classroom interaction

Inquiry involves questions. Inquiry-based teaching could easily be interpreted as merely "asking questions" or perceived as an analogy for communicative approach by foreign language instructors. Nevertheless, it is a pedagogical approach as well as a learning strategy. Through the use of questioning, the core value of inquiry-based pedagogy puts stress on discovery learning and the development of learners' cognitive skills and metacognitive strategies.

\section{A Glance over Foreign Language EduCATion}

Second or foreign language (L2) teaching is a profession filled with vigor and innovations. The development of language teaching methodology has undergone several stages over the last century. A variety of approaches has emerged either in response to new thoughts or as a reaction to the inadequacies or drawbacks of an earlier method. These scholastic debates reflect different viewpoints and perspectives revolving around theories of language acquisition, purposes of language learning as well as goals and the mechanics of language instruction. The swing of the pendulum continued until communicative language teaching (CLT) achieved its prominence and changed the face of L2 teaching (Canale \& Swain, 1980; Littlewood, 1981; Savignon, 1991, 2001). It was advocated that, in addition to the linguistic competence (Paulston, 1974) or the study of grammar, acquiring communicative competence (Hymes, 1972; Brown, 1994) is vital to the success of L2 learning. Since then, consensus has been reached that the purpose of L2 learning and the mission of L2 teaching are to build up the ability to function and interact appropriately with people of the target language in a real social setting. The best way to acquire communicative competence is to communicate through meaningful interactive activities in which authentic language can be exercised while the negotiation of meaning takes place. Task-based instruction (TBI) (Skehan, 1998; Willis, 2004), or task-supported teaching, is thus evolved as a supplement to CLT and it is assumed that TBI stimulates natural acquisition processes (Prabhu, 1987). Due to the impact of CLT and TBI, the teaching practice thus weights more on the enhancement of students' active participation and the meaningful exchange of information in a simulated real-life context. Accordingly, the teacher's ability to construct a dynamic teaching scheme becomes crucial, and the question-answer interactive module is an indispensable component.

Though CLT has been applied and interpreted in a broad sense and has become the mainstream in present-day L2 education, it does not imply that other approaches are of no use or are incompatible. For instance, while the method of grammar translation is obsolete, research revealed that explicit teaching of grammar at some point in instruction is still necessary so as to improve the level of accuracy (Ellis, 2006) or to achieve a higher level of proficiency (Leaver \& Atwell, 2002). In examining all approaches and methods, it comes as no surprise to note that similarities exist and that distinctive features complement one another. CLT has been described as an approach rather than a specific teaching method or strategy (Richards \& Rodgers, 1986), as indicated in their conclusion on CLT that “... at the levels of design and procedure there is much greater room for individual interpretation and variations than most methods permit." (p. 
83). It is noteworthy to search for a balance between pure communicative teaching and the practice of form-focused instruction. A skillful teacher, taking the philosophy of CLT as the foothold, is capable of implementing an effectual pedagogical application from a variety of available resources which satisfies the CLT objectives and leads to optimal learning outcomes. While an abundance of teaching methodology has been devoted exclusively to the field of language education, the domain-independent theories and models of instructional design may equally contribute inspiring ideas and provide teachers with alternative options. Amongst them, the model of inquiry teaching, a cognitive approach, is a perfect match which echoes the concerns and demands of today's L2 teaching - that is, to foster an interactive and communicative teaching/learning environment while supporting discovery, reflective and creative learning.

\section{INQUIRY-BASED SECOND/FOREIGN LANGUAGE PEDAGOGY}

\section{A. What Is Inquiry-based?}

Learning is deeply rooted in profound thinking and thinking is inspired by questions. Inquiry teaching (Collins \& Stevens, 1983; Collins, 1987) is a cognitive educational theory as well as a teaching practice. Unlike other theories, it was first developed inductively by studying transcripts and analyzing the strategies employed by a number of teachers in different domains. The studies disclosed that all those expert teachers made use of some sort of inquiry, discovery, or Socratic approach to teaching.

As the name suggests, inquiry teaching, versus expository teaching in which the teacher expounds all the information, involves the use of questioning as the major vehicle to present the material and deliver instruction. The questions being asked in class outline the focus and direction of the lesson content. Distinct from the routine question-answer information exchange, the inquiry-based teaching lays special emphasis on the core concepts of cognitive and discovery learning and its goal to develop higher-order thinking. In other words, teachers do not teach everything directly or explicitly. Instead, learners are expected and encouraged to discover the knowledge, to generate underlined rules based on a series of examples and counterexamples, and to be able to further apply these rules or knowledge to novel cases and deal with everyday life situations. The teacher thus becomes the facilitator to assist learners in exploring and constructing their conceptual system. It is evident that this type of teaching challenges students more when compared with the teacher-directed teaching mode. By turning lecturing into problem solving, this approach promotes deeper understanding and inspires learners' cognitive capability by the virtue of active engagement in the learning process.

\section{B. Why Inquiry-based?}

Although this instructional model has primarily been applied to the teaching in science and math, its concept and question-answer mechanism are equally well-suited to L2 classroom. Instructors employ the inquiry technique to enhance the acquisition of vocabulary, to explore the grammatical structures, to engage in the negotiation of meaning and to discover the embedded cultural essence. This practice helps ensure the L2 learning experience stays active and dynamic which in turn keeps students engaged and attentive.

The implementation of inquiry teaching benefits second language instruction in all aspects. It not only serves the purpose of increasing the opportunity of participation and maintaining students' attention, it is an instrument to initiate and sustain the instructional interaction. Through questioning, the teacher is able to probe into the pattern of errors made by students and their levels of comprehension as well as to make judgment and assessment on the learning outcomes. It is also anticipated that the inquiry-based teaching approach strengthens both students' linguistic and communicative competence. Following in the spirit of CLT and TBI, the ideal condition is to integrate various types of questions into a meaningful context in a natural sequence.

An effective inquiry technique is a valuable expertise language educators should possess. Good questions not just provide exciting and challenging learning experience, they allow discovery, reflection and creativity, and ignite cognitive and metacognitive skills as well which by all means facilitate self-regulated learning and future learning transfer. What should be kept in mind is that the mission of being a second language educator is not just to disseminate linguistic knowledge. It is of equal importance to assist students understand and control their learning, and to enlighten them on making good use of cognitive and metacognitive strategies.

\section{Types and Functions of Questions}

Virtually every language pedagogue undertakes inquiry teaching to a certain extent in some form, but what and how to ask is of concern. It is not uncommon that many teachers experience difficulties in motivating students to enthusiastically participate or in sustaining the duration of meaningful interaction. Needless to say, teachers feel frustrated as their teaching practice fails to elicit the desired output. This predicament may be attributed to inadequate preparation on students' part, mismatch between questions and learners' proficiency level, or the dullness of questions that are ineffective in eliciting prolific responses or critical thinking. Students may get bored when questions are not challenging, are beyond their capability, or are not personally associated. There is no doubt that the effectiveness of the inquiry skill and the appropriate choice of questions directly impact the quality of teaching and achievement of learning. On that account, the selection of questions along with the sequence and pattern of delivery are of great importance in the stages of planning and implementing. 
In everyday activities, a common intent of asking questions is to either obtain information or garner attention from the listener. Whereas, questions with instructional purpose are somewhat distinct from those used in natural discourse in both type and function. Kearsley (1976) proposed a framework after examining the syntactic forms and semantic functions of questions in ordinary verbal discourse. This taxonomy consists of four groups of questions, namely echoic, epistemic, expressive and social control, based on the function a question serves. Obviously, from the pedagogical perspective, the first two categories account for most of the classroom catechism. In most cases, teachers ask direct questions which consist of open-end wh-questions and closed-end alternative or yes/no form.

Limited research has been done pertaining to the types of language teachers' questions and the relationship between the cognitive level of questions and students' performance. Following Kearsley's analytic work, Long and Sato (1983, 1984) investigated the questioning by ESL teachers and an elaborated and expanded taxonomy was established which better reflected teachers' inquiry tendency in a formal learning setting. The findings confirmed that echoic and epistemic questions are the two types most utilized by language teachers. Echoic questions usually serve the purpose of requesting repetition of an utterance, clarifying vagueness, or confirming the words and intention to be conveyed. In the category of epistemic questions, which are used to acquire or exchange information, the research evidence manifested the significant preference for display questions over referential questions during instruction. The former refers to those to which the questioner already knows the answer, the latter are questions to which the responses may vary and not be known or predicted by the questioner. Referential questions are those involving exchange and negotiation of meaning and are most often heard in real life communication.

Research (Brock, 1986) also pointed out that students improved their answers both in quality and quantity when they were asked referential questions. In other words, learners tend to produce longer and more syntactically complex sentences when responding to referential rather than display questions. Moreover, compared with closed referential questions to which either one or very limited answers are possible, open referential questions seemingly draw forth more fruitful responses.

It is no surprise to learn that language teachers ask significantly more display questions given that display questions are mostly text-based or relate to the material being covered. This type of question is postulated to enhance learners' comprehension of specific content as well as a means to verify if the material has been transmitted and absorbed by students. Nevertheless, if classroom interaction is carried out predominantly by asking display questions, little genuine communication or negotiation of meaning can be achieved. This inclination somewhat signified that, practically or as a conventional practice, teachers tend to focus on linguistic competence more despite the widespread belief in communicative teaching. Yet, teachers can be trained to advance their elicitation skills with the increase of the number of referential questions (Long \& Sato, 1984; Jin, 2004).

Furthermore, display questions are assumed to be at the low cognitive levels according to Bloom (1956) and Gagné's (1985) classification of the cognitive domain, because they are mainly used to recall or memorize factual information. Referential questions, however, are likely to call for higher cognitive skills, such as the application of learned vocabulary and structures in new context, or the provision of opinions and comments after making judgment or evaluation. But this does not mean that display questions are of no use. A balance of a variety of questions should be attained.

The revised Bloom's taxonomy can be useful when adopted as the guidelines of questioning (see Table 1). The revision in 2001 (Anderson \& Krathwohl, 2001) used action verbs to label skills or processes encountered in different levels of cognition, and a simplified three-level version was also proposed for a broader use (Walsh \& Sattes, 2005). It is recommended that teachers be able to design and organize questions and activities insofar as these cognitive skills or abilities can be exercised. Different types of questions lead to different levels of performance. It is important to use as many question types as possible. Though upper-level types are more desirable, which require further efforts and deliberation of students, lower levels serve the foundation of moving upwards.

TABLE 1

BLOOM'S TAXONOMY AND TWO REVISED VERSIONS

\begin{tabular}{|l|l|l|}
\hline $\begin{array}{l}\text { Bloom's Taxonomy } \\
\text { (Bloom, 1956) }\end{array}$ & $\begin{array}{l}\text { Revised } \\
\text { (Anderson \& Krathwohl, 2001) }\end{array}$ & $\begin{array}{l}\text { Revised } \\
\text { (Walsh \& Sattes, 2005) }\end{array}$ \\
\hline Knowledge & Remember & Recall \\
\hline Comprehension & Understand & Use \\
\hline Application & Apply & \\
\hline Analysis & Analyze & \multirow{2}{*}{ Create } \\
\hline Synthesis & Evaluate & \\
\hline Evaluation & Create & \\
\hline
\end{tabular}

In addition to enhancing discovery learning and cognitive skills, questions can be utilized to provoke metacognitive skills. Metacognition is generally defined as "thinking about thinking." It involves preparing and setting learning goals, choosing and using appropriate and effective learning strategies in a given task, and monitoring and evaluating one's own learning (Anderson, 2002). A person who is aware of metacognition knows how to deal with his/her learning effectively. They have the knowledge and ability to manage their own thinking processes. Profound learning happens when students are involved in reflecting, thinking and reasoning. Learners learn and are aware of metacognitive skills 
when questions stimulate higher-order thinking; and these skills support regulating, supervising and assessing their L2 learning.

\section{AdDitional CONSIDERATIONS OF INQUiRy-BASED TEACHING}

\section{A. The Adaptability of Questions}

The appropriateness of questions and the pattern of presentation are closely related to the effectiveness of teaching and the development of students' linguistic capabilities. As discussed previously, referential questions function more productively than display questions in terms of communication. Though display questions are necessary and suitable for teaching low cognitive level factual knowledge, such as vocabulary and the recall or recognition of textual information, referential questions are able to trigger students' interest and allow them to express themselves which in turn brings on heated discussions. Questions should also deal with upper level cognition, such as asking students to derive grammatical rules inductively or to provide solutions in the target language to situations encountered. It is important to keep in mind that the higher the proficiency level of the class, the more referential questions are called for.

Questions should be in accordance with students' level of proficiency, that is, students have acquired sufficient lexical items and grammatical structures to render responses. Moreover, teachers need to be perceptive to students' reaction and be flexible in adjusting questions according to learners' performance so as to refrain them from languid or unresponsive replies, such as a simple yes/no or simply "I don't know." For pedagogical purposes, questions can be used as a device to control the production of desired outcomes. Teachers are supposed to be able to develop questions wittingly in such a way as to elicit or force the use of certain vocabulary and particular sentence structures during a given task.

\section{B. Delivery of Questions in a Meaningful Spiral Form}

Learning is a cognitive process involving the accumulation of knowledge. In learning theories, Ausubel (1968) deliberated that learning must be meaningful to be effective and long-lasting. Learning is meaningful only when the new material connects or anchors to one's existing cognitive framework or relevant previously-learned knowledge, or, the learning task is potentially relatable to learner's personal experience or regular activities. The association of new information with previously acquired entities and the comparison between similar elements are regarded as effective cognitive strategies to create mental linkages. Based on this assumption, teacher's questions should stem from a meaningful context and administer in a spiral form. Questions are deliberately organized to elicit responses expanding from vocabulary and phrases to complex sentences; from who, what, where and when to how and why. When the material is presented in an expanded spiral pattern, the increment of lexicon and syntactic structures is built up progressively in a meaningful manner. The spiral scheme brings old information into the working memory and associates with new content which reinforces the retention by refreshing memory and by adding linguistic components through circulating reiteration.

\section{Students Taking the Floor}

Learning doesn't happen when you simply sit in the classroom and listen. It is essential to make learners active partners in the learning process instead of passive recipients waiting for information to be given. More than often, we found that students are capable of offering answers other than initiating inquiry, which is partly due to the fact that the teacher is frequently the questioner in a conventional classroom. Teachers should act as facilitator or guide as advocated by many language educators. In the inquiry-based teaching, however, every student is encouraged and given equal opportunity to be the inquirer. This role shifting can be achieved by modeling or providing students with explicit guidelines.

The instructor demonstrates questioning before giving the floor to students for their attempt at inquiry, either in a whole class setting or in small groups. Questions can be those pertaining to the text or open-ended types relating to reallife or personal experience. Nevertheless, the success of such peer interaction counts on factors such as the quality of questions, willingness of participation, preparation for class, or the trust and dynamics among students. In this case, the teacher's role as a catalyst is evident in the entire process. It is essential for L2 learners to be able to make inquiries in the target language given that it is an unavoidable component in problem solving as well as in natural discourse.

\section{Accompaniment of Extra-linguistic Visual Support}

A wide range of variables has been identified to contribute and determine the success of L2 learning, such as cognitive, affective and socio-cultural factors (Brown, 1987). Among them, the learning style is a collection of cognitive parameters which refers to a person's consistent tendencies or preferences in learning, and sensory preference is one of the significant characteristics. Sensory preference is "the physical, perceptual learning channels with which the student is the most comfortable." (Oxford, 2001, p.360) Classroom language teaching usually involves visual and auditory stimulus. Auditory students are comfortable with lectures and oral activities. In contrast, visual students benefit tremendously from instruction with visual backup. Studies have shown that the provision of appropriate contextual visual aids significantly facilitated both listening and reading comprehension in students of lower proficiency levels (Omaggio, 1979; Mueller, 1980; Liu, 2004; Abraham, 2007). 
Inquiry-based teaching assuredly can be enhanced by the support of carefully selected visuals or authentic material. Along with the advances of technology and the prevalence of smart classrooms, the integration of multimedia makes classroom presentation appealing and informative. Inquiry teaching accompanied by visuals or multimedia provides prompt or extra support to the content being discussed, makes learning more comprehensible and invigorates the interactive spirit.

\section{The IMPLEMENTATION OF INQUIRY TEACHING: SOME EXAMPLES}

The inquiry teaching method works best on theme-based texts on the grounds that coherent instructional discourse can proceed on specific topics and brings out new expressions and patterns in a progressive manner. In lieu of teaching vocabulary explicitly, the teacher elicits new words of the text from students by asking display questions. Visuals can be presented to give cues or prompt for the desired output. Referential questions are employed to relate the content to personal experience which makes the learning more significant and at the same time further linguistic information may be introduced during the interaction. Students take the floor when they have received sufficient input to engage in paired or group tasks.

Example 1: A series of questions can be applied to the topic of shopping in a supermarket, from simple informationseeking to the solicitation of opinions and comments. (The following questions are delivered in the target language.)

Ask students to name items found in a supermarket, such as fruit, vegetables, meat, beverages, daily necessities, etc.

What do you have for breakfast?

What stuff will you prepare for a birthday party?

Where can these things be purchased?

What supermarkets do you have near your house?

How often do you go to the supermarket? And with whom?

Which market do you go to most often? Which one do you like or not like?

Why do you like this supermarket?

Example 2: One student acts as the instructor and asks his peer students questions based on the lesson content or by the use of visuals. The protocol of selecting this leading student can be volunteering, taking turns, or by lottery.

Learning is more effective if questions enable learners to access relevant prior-learned knowledge when new information is being acquired. The teacher invites students to participate in tasks involving higher cognitive skills of connection, association, contrast and inference. These skills are key strategies that support learners to internalize information. Activities such as exploring and distinguishing between words with phonological, orthographical, or semantic similarity are likely to clarify ambiguities and reinforce the appropriate usage of words.

Example 3: After learning the word for "breakfast" in Chinese, ask students to form compound words with similar structure by the retrieval of previously acquired information. This is an excellent way to expand the lexical capacity.

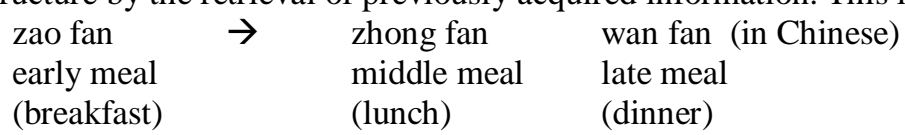

Example 4: Ask students to use learned vocabulary to give definition or explain new words or concept.

jiaoshou $\rightarrow$ daxue de laoshi (in Chinese)

(professor) (college teacher)

woshi $\rightarrow$ shuijiao de fangjian $\quad$ (in Chinese)

(bedroom) (sleep room)

The integration of inquiry-based discovery pedagogy into grammar learning leads students moving beyond rule memorization. New sentence structures are examined and acquired through observation and analysis. Teachers should encourage risk-taking and commend good guessing or successful attempts because risk-taking and guessing are vital characteristics of good second language learners (Brown, 1987). Although learning strategies are used by learners themselves, it is yet the teacher's responsibility to stimulate and direct students to exploit and develop these strategies which benefit the overall learning process and promote self-monitoring.

Example 5: Ask students to examine the difference between Chinese (the target language) and English (their native language) on the passive voice structure.
$\mathrm{Yu}$ bei mao chi le.
(in Chinese)
fish passive cat eat perfective aspect marker marker

(The fish was eaten by the cat.)

Example 6: Ask students to explore the structure of locative phrases in Chinese and contrast with that in English.

Yinhang zai tushuguan de zuobian. (in Chinese)

bank locate library marker left

Tushuguan de houbian shi yinhang. (in Chinese)

Library marker back is bank

(The bank is on the left of the library.) 
Example 7: Ask students to explain the process of forming wh-questions in Chinese. Does it involve substitution or movement?
Ta qu nar?
he go where (Where does he go?)
$\mathrm{Ni}$ zai nar gongzuo? (in Chinese)
you at where work (Where do you work?)
Zhei shi shenme? (in Chinese)
this is what (What is this?)
Shei shi nide laoshi? (in Chinese)

who is your teacher (Who is your teacher?)

One of the main goals of learning a language is to be able to cope with situations or troubles encountered in the community of the target language. Thus, problem-solving involving the application of existing knowledge to possible circumstances should be treated as an integral component in L2 learning. It is beneficial to students if activities are designed to impose questioning on students.

Example 8: A destination on a map is pre-selected by the teacher. Students need to find out where this spot is by generating questions. For instance:

Wo yao zuozhuan haishi youzhuan? (Should I make a left turn or a right turn?)

Zai zuobian haishi youbian?

Yao guo ji ge honglüdeng?

Zai nar xiache?

(Is it on the left side or right side?)

(How many traffic lights are there to pass?)

Example 9: The teacher announces that there is a great concert in town. Let students get more information about it by asking questions in the target language, such as:

When is the concert?

What kind or whose concert is it?

Where is it?

How much is the admission?

How can I get there?

Who is interested in attending this event?

\section{FeEdback on InQuiRY-BASEd Teaching: A Qualitative Study}

\section{A. Participants and the Instrument}

After the implementation of the inquiry-based teaching method for one semester, a questionnaire (see Table 2) was administered to explore the effectiveness of and students' attitudes toward the inquiry-based teaching. A total of eleven students from a small-scale liberal arts college participated in this study. They enrolled in the second semester of the first year Chinese language class and were all continuing students from the first semester class. Seven of them were males and four were females ranging in age from 19 to 22 years old. There were six freshmen, two sophomores, two juniors and one senior. All of them were non-Chinese and non-native speakers of the Chinese language. The questionnaire was distributed to collect qualitative data anonymously at the end of the semester. It contained 16 statements in regard to aspects such as attentiveness, motivation, anxiety, class interaction, the use of visuals as well as general thoughts on this particular teaching approach. The score is on a 5-point scale, ranging from 1 (the lowest, disagree) to 5 (the highest, agree).

\section{B. Research Questions}

In addition to disclosing the general impression, the questionnaire was intended to confirm the following six assumptions on inquiry-based teaching:

(1) fosters an effective and meaningful learning experience;

(2) enhances learning motivation;

(3) keeps learners attentive;

(4) increases the amount of classroom interaction and participation;

(5) is more effective when supported by the use of visual aids or multimedia; and

(6) may raise the classroom anxiety level on some students.

\section{RESULTS AND DISCUSSION}

On Learning Motivation (Question \#2):

Eight out of eleven students fully agreed that inquiry teaching enhanced their motivation in learning the target language. Motivation has been a decisive factor for explaining the success or failure of virtually any given task. Motivation has long been proved in research to be positively correlated with learning achievement (Gardner \& Lambert, 1972; Masgoret \& Gardner, 2003), and highly motivated individuals are usually successful in learning.

On Classroom Attentiveness (Questions \#5 and 6): 
Gaining learners' attention is the initial task in Gagne's (1985) events of instruction, and it is a key to make the act of learning occur. In this survey, the majority of students acknowledged that they were more attentive when the teacher was engaging in inquiry teaching. It confirmed that the dynamics of question-answer process keeps students more concentrated and away from distractions.

On Interaction and Participation (Questions \#8, 9, 10, and 11):

As predicted, almost all students concurred that the inquiry teaching strategy did provide students with greater interactive opportunities and encouraged them to actively join activities or discussions. In general, students' responses indicated it was quite effective in initiating and sustaining teacher-student interaction. The learning atmosphere becomes vigorous when students take the floor fervently.

On the Use of Visual Aids (Question \#12):

It is not surprising to learn that our digital-native students unanimously assented to and were in favor of the adoption of visuals accompanying inquiry teaching. Visual aids include those delivered via new technology as well as flash cards, realia, or body gestures found in a traditional classroom. This result upholds the assumption that multimedia facilitates the language teaching and learning process and is very welcomed by students as it increases students' comprehensibility and allows classroom learning to be more relaxed and enjoyable.

TABLE 2

RESULTS OF THE QUESTIONNAIRE ON INQUIRY-BASED TEACHING

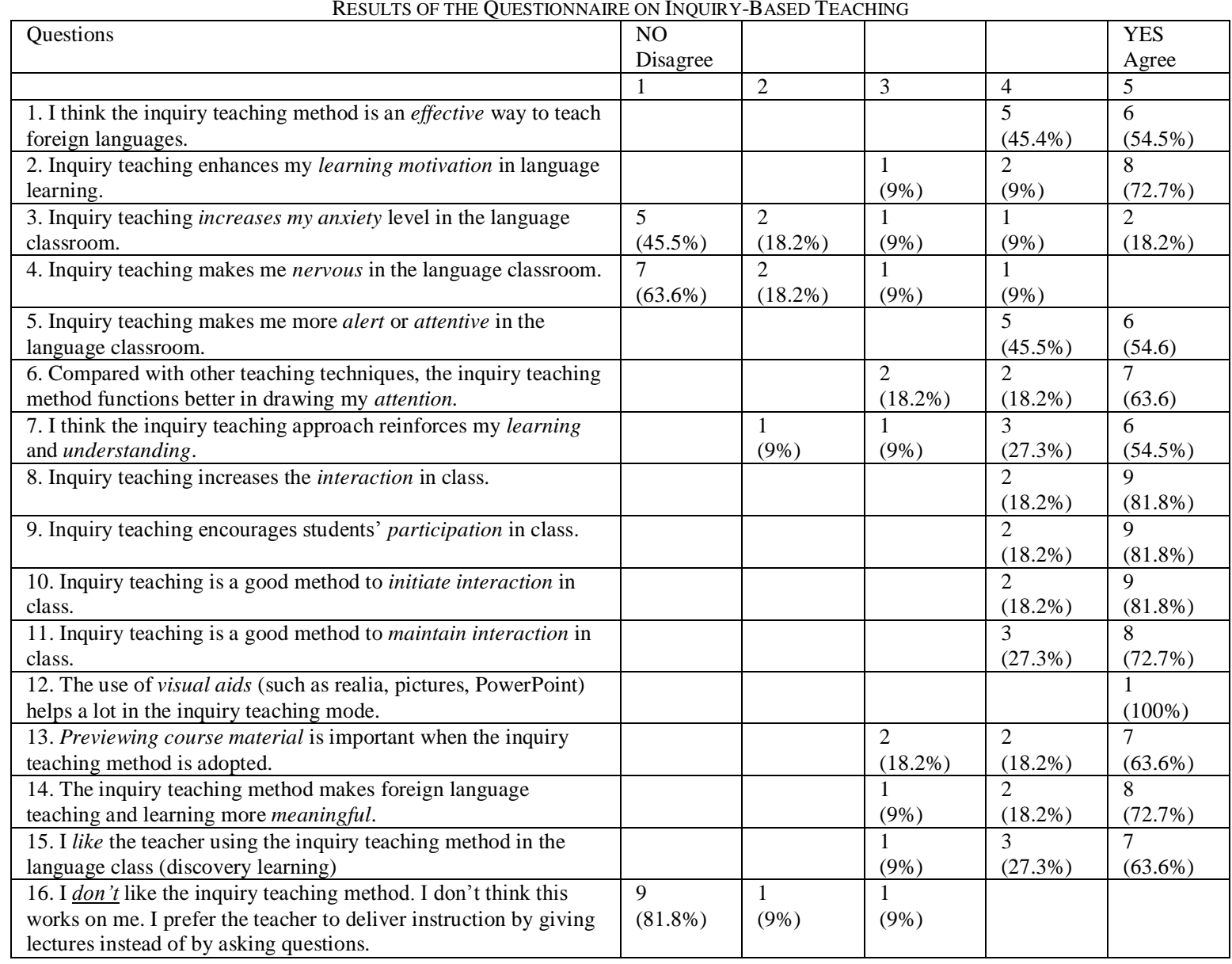

\section{On Classroom Anxiety (Questions \#3 and \#4):}

Though three students $(27 \%$ on question \#3) reported that inquiry teaching was most likely to augment their level of anxiety, more than half of students did not experience negative impact. Anxiety has been identified as an important affective factor and has long been a focus in the L2 education and research (Horwitz, Horwitz \& Cope, 1986; Horwitz \& Young, 1991; Zhao \& Whitchurch, 2011). It is generally considered to be negative correlated with the performance of learning. Despite the fact that too much anxiety may be an obstacle and hinder one's learning, it may function as a facilitative force when it is at the optimal level. The appropriate level of tension is constructive and can drive the student to make efforts and to get the job done. Teachers should be aware of this effect by creating a less-stressed learning environment when the inquiry teaching is adopted.

On Preparation of the Lesson (Question \#13):

One of the questions was intended to look at what students think about the importance of previewing the lesson. Previewing the course material before coming to class is a helpful learning practice which keeps up with the pace of instruction. The data shows most of the students agreed that acquainting themselves beforehand with the upcoming 
lesson is important when the teacher conducts a form of discovery teaching. Students without preparation may lose opportunities of interaction and feel embarrassed or disoriented when he/she is called on. Whereas, students who come to class prepared are inclined to interact actively and receive more attention from the teacher. It is anticipated that inquiry teaching would urge students to form a good study habit.

On the Inquiry-Based Teaching Approach (Questions \#1, 7, 14, 15 and 16):

Five questions were designed to collect opinions on this teaching style. It was found that, although one student expressed reservations, most students were in favor of this inquiry approach. They preferred inquiry teaching rather than expository lecturing, and considered this pedagogical method to be effective and meaningful.

\section{CONCLUSION}

"Tell me and I forget, show me and I remember, involve me and I understand." Inquiry-based teaching practice is an excellent paradigm of this old adage. An advanced version of CLT and an expansion of TBI per se, inquiry-based teaching sets out to inspire and develop students' higher levels of learning by involving them linguistically and cognitively. Beyond memorization of facts, carefully structured questions enable learners to connect, apply, analyze and create.

Students were positive, by and large, on the inquiry-based instructional approach. Responses from the assessment manifest that this type of Socratic teaching is valid and efficacious as an approach in L2 instruction. The choice of appropriate types of questions and the scheme in presenting them play essential roles and account for the success of this method. Teachers need to integrate the vocabulary and grammatical structures intended to be taught into questions and deliver them in a recurrent pattern. A natural and meaningful information exchange is likely to take place when questions are organized in a logically sequenced format and are relevant to both contextual and personal experience so as to elicit students' interest and participation. In addition to assessing the comprehension of instructional material, questions should be able to activate and exploit cognitive and metacognitive strategies. Discovery L2 teaching allows students to gain better insights into the target language and their native languages as well. Furthermore, the sound utilization of visual/multimedia resources has been illustrated as a highly favorable feature complementing the inquiry instructional process.

Some variables that might affect the successful implementation of inquiry-based teaching include the nature of the student group and the instructor's ability to create a relaxed and pleasant learning environment. It goes without saying that a good rapport and trust between teacher and students are essential elements. Students may feel coerced if the instructor is too dominating or does not give them enough time to think before rendering an answer or solution.

While the results of the present study might not be significant enough given the small number of subjects, they do provide preliminary evidence which exhibits encouraging feedback and demonstrates a preference for this interactive and discovery teaching method. In order to obtain a fuller picture on the effectiveness of inquiry-based teaching, a sample of a larger number of participants is recommended in future studies. Prospective lines of study may deal with the investigation of the effects of inquiry teaching on students' proficiency level and language performance as well as correlation analyses between ratings on inquiry teaching and selected affective or cognitive variables of learners.

\section{REFERENCES}

[1] Abraham, L. B. (2007). Second-language reading comprehension and vocabulary learning with multimedia. Hispania, 90(1), 98-108.

[2] Alberta Learning. (2004). Focus on Inquiry: A teacher's guide to implementing inquiry-based learning. ERIC number: ED491498. http://files.eric.ed.gov/fulltext/ED491498.pdf (accessed 20/1/2014).

[3] Anderson, L. W. \& D. R. Krathwohl. (2001). A taxonomy for learning, teaching, and assessing: A revision of Bloom's taxonomy of educational objectives. New York: Longman.

[4] Anderson, N. J. (2002). The role of metacognition in second language teaching and learning. ERIC Digest, EDO-FL-01-10. http://www.gpo.gov/fdsys/pkg/ERIC-ED463659/pdf/ERIC-ED463659.pdf (accessed 22/1/2014).

[5] Ausubel, D. (1968). Educational psychology: A cognitive view. New York: Holt, Rinehart and Winston.

[6] Bloom, B. S. (Ed.) (1956). Taxonomy of educational objectives: Cognitive domain. New York: David McKay.

[7] Brock, C. A. (1986). The effects of referential questions on ESL classroom discourse. TESOL Quarterly, 20.1, 47-59.

[8] Brown, D. H. (1987). Principles of language learning and teaching. New Jersey: Pentice-Hall, Inc.

[9] Brown, D. H. (1994). Teaching by principles: An interactive approach to language pedagogy. New Jersey: Prentice Hall Regents.

[10] Canale, M. \& M. Swain. (1980). Theoretical bases of communicative approaches to second language teaching and testing. Applied Linguistics, 1, 1-47.

[11] Collins, A. \& A. Stevens. (1983). A cognitive theory of inquiry teaching. In C. M. Reigeluth (ed.), Instructional-design theories and models: An overview of their current status. New Jersey:Lawrence Erlbaum Associates Publishers, 247-278.

[12] Collins, A. (1987). A sample dialogue based on a theory of inquiry teaching. In C. M. Reigeluth (ed.), Instructional theories in action: Lessons illustrating selected theories and models. New Jersey: Lawrence Erlbaum Associates Publishers, 181-199.

[13] Crookes, G. \& C. Chaudron. (2001). Guildlines for language classroom instruction. In M. Celce-Murcia (ed.), Teaching English as a second or foreign language. Boston, MA: Heinle \& Heinle, 29-42.

[14] Ellis, R. (2006). Current issues in the teaching of grammar: An SLA perspective. TESOL Quarterly, 40.1, 83-107.

[15] Gagné, R. M. \& L. J. Briggs. (1979). Principles of instructional design. New York: Holt, Rinehart, \& Winston. 
[16] Gagné, R. M. (1985). The conditions of learning. New York: Holt, Rinehart \& Winston.

[17] Gardner, R. C. \& W. E. Lambert. (1972). Attitudes and motivation in second language learning. Rowley, MA: Newbury House Publishers.

[18] Horwitz, E. M. Horwitz, \& J. Cope. (1986). Foreign language classroom anxiety. Modern Language Journal, 70, $125-132$.

[19] Horwitz, E. K. \& D. J. Young. (1991). Language anxiety: From theory and research to classroom implications. Upper Saddle River, NJ: Prentice Hall.

[20] Hymes, D. (1972). On communicative competence. In J. B. Pride and J. Holmes (eds.), Sociolinguistics. Harmondsworth, U.K.: Penguin Books.

[21] Jin, H. G. (2004). The importance of CFL teacher training on elicitation techniques. Journal of the Chinese Language Teachers Association, 39.3, 85-110.

[22] Kearsley, G. P. (1976). Questions and question asking in verbal discourse: A cross-disciplinary review. Journal of Psycholinguistic Research, 5.4, 355-375.

[23] Leaver, B. L. \& S. Atwell. (2002). Preliminary qualitative findings from a study of the processes leading to the advanced professional proficiency level (ILR4). In B. L. Leaver \& B. Shekhtman (eds.), Developing professional-level language proficicency. Cambridge: Cambridge University Press.

[24] Littlewood, W. (1981). Communicative language teaching: An introduction. Cambridge: Cambridge University Press.

[25] Liu, J. (2004). Effects of comic strips on L2 learners' reading comprehension. TESOL Quarterly, 38.2, 225-243.

[26] Long, M. H. \& C. J. Sato. (1983). Classroom foreigner talk discourse: Forms and functions of teachers' questions. In H. W. Seliger \& M. H. Long (eds.), Classroom oriented research in second language acquisition Rowley. MA: Newbury House, 268285.

[27] Long, M. H. \& C. J. Sato. (1984). Methodological issues in interlanguage studies: An interactionalist perspective. In A. Davies, C. Criper \& A. Howatt (eds.), Interlanguage. Edinburgh: Edinburgh University Press, 253-288.

[28] Masgoret, A. M. \& R. C. Gardnes. (2003). Attitudes, motivation, and second language learning: A meta-analysis of studies conducted by Gardner and associates. Language Learning, 53, 123-163.

[29] Mueller, G. A. (1980). Visual contextual cues and listening comprehension: An experiment. The Modern Language Journal, 64.3, 335-340.

[30] Omaggio, A. C. (1979). Pictures and second language comprehension: Do they help? Foreign Language Annals, 12.2, 107-116.

[31] Oxford, R. L. (2001). Language learning styles and strategies. In M. Celce-Murcia (ed.), Teaching English as a second or foreign language. Boston: Heinle \& Heinle, 359-366.

[32] Paulston, C. (1974). Linguistic and communicative competence. TESOL Quarterly, 8, 347-362.

[33] Prabhu, N. S. (1987). Second language pedagogy. Oxford: Oxford University Press.

[34] Richards, J. C. \& T. S. Rodgers. (1986). Approaches and methods in language teaching: A description and analysis. Cambridge: Cambridge University Press.

[35] Savignon, S. J. (1991). Communicative language teaching: State of the art. TESOL Quarterly, 25.2, 261-277.

[36] Savignon, S. J. (2001). Communicative language teaching for the twenty-first century. In M. Celce-Murcia (ed.), Teaching English as a second or foreign language. Boston, MA: Heinle \& Heinle, 13-28.

[37] Skehan, P. (1998). Task-Based instruction. Annual Review of Applied Linguistics. 18, 268-286.

[38] Walsh, J. A. \& B. D. Sattes. (2005). Quality questioning: Research practice to engage every learner. Thousand Oaks, CA: Corwin Press.

[39] Willis, J. R. (2004). Perspectives on task-based instruction: Understanding our practices, acknowledging different practitioners. In B. L. Leaver \& J. R. Willis (eds.), Task-based instruction in foreign language education. Washington, D.C.: Georgetown University Press, 3-44.

[40] Zhao, A. \& A. Whitchurch. (2011). Anxiety and its associated factors in college-level Chinese classrooms in the US. Journal of the Chinese Language Teachers Association, 46.3, 21-47.

Horng-Yi Lee received her M.A. degree in Chinese literature and Ph.D. in education, with emphasis on second language pedagogy. She is currently an assistant professor in the department of Modern Languages and Literature at Whittier College in California, USA. She teaches all levels of Chinese language courses, introduction to Chinese linguistics, Chinese poetry and short stories. Her research interests are mainly in second language pedagogy and Chinese morphology. She has served on the editorial advisory board of McGraw-Hill Companies, Higher Education. 